\title{
Effects of Urban Land Use/Cover Dynamics on Peri-urban Natural Environmentin Nekemte City, Oromia, Ethiopia
}

\author{
Tolera Megersa*, Taffa Tulu, Mekuria Argaw \\ Center for Environmental, Addis Ababa University, Addis Ababa, Ethiopia
}

Email address:

toleramegersa@gmail.com (T. Megersa)

${ }^{*}$ Corresponding author

\section{To cite this article:}

Tolera Megersa, Taffa Tulu, MekuriaArgaw. Effects of Urban Land Use/Cover Dynamics on Peri-urban Natural Environmentin Nekemte City, Oromia, Ethiopia. International Journal of Energy and Environmental Science. Vol. 3, No. 3, 2018, pp. 51-60. doi: 10.11648/j.ijees.20180303.11

Received: April 12, 2018; Accepted: May 14, 2018; Published: June 4, 2018

\begin{abstract}
The urbanization process has led to the steady growth of cityat the expense of peri-urban natural environment. This study was conducted in the Nekemte city, Oromia Region at Western part of Ethiopia. The research was aimed to assess the effects of urban land use/ cover dynamics on natural environment through the interpretation of three years' time series images and psycho-chemical analysis of surface water quality of the study site. Land use classification maps were developed by using geos patial methods, remote sensing and Geographic Information System (GIS). Study area land use/ cover mapping and change detection analysis was conducted by Arc-GIS software. Urban land use and cover dynamic analysis revealed that built-up areas have been increased during 1996 to 2016 resulting in substantial reduction of forest area, cultivated land, grazing land, wetland and riparian forest. Forest and wetland, which are the focuses of this research, have been continuously decreased from $17 \%$, and $14 \%$ in 1996 to $5.1 \%$ and $2.7 \%$ in 2016 , respectively, with an average annual urban growth rate of $3.65 \%$ within 20 years, resulted in an increased mean annual local temperature, variability of rainfall and relative humidity and surface water quality reduction. Projected values indicated that built up areas will be increased continuously for the coming 10 years. Continuous conversion of forest, wetl and land and other land cover type to urban land had resulted into varied and extensive natural ecosystem disturbances; local climate change biodiversity loss and surface water quality reduction. Population growth, migration and economic development are the main identified factors contributing for urban land expansion. Impacts of urban expansion on peri-urban environment can be reduced through controlling population growth and incorporating environmental issues in any urban and economic development program.
\end{abstract}

Keywords: Geographic Information System, Land Use/Cover, Urban Land

\section{Introduction}

The world is under going the largest wave of urban growth in history. According to the United Nations Population Fund [9], rapid population growth has been concentrated in towns and cities of the world. The report also projected that by the year2030 the vast majority of this growth will be observed in the developing world of Africa and Asia where urban growth is highly concentrated. Because cities offer a lot of opportunities such as jobs and sources of income than the corresponding rural areas, they attracted a lot of people. Urbanization, especially in the developing world is frequently accompanied by the deterioration of the urban environment. It leads to the impairment of human health, economic and other welfare losses and damage to the urban ecosystem. Air and water pollution, inadequate waste management and reduction of green areas are frequently the major environmental problems. Conversion of open, green spaces to urban development reduces water- permeable areas, upsets natural drainage patterns and causes serious flooding [3], with subsequent damage to dwellings and infrastructure and sometimes involving even human casualties.

Expansion of agriculture, urbanization, deforestation and the day today activities of mankind resulted to temporal and spatial change inland use land cover have affected water flow path ways and water balance Developing countries like Ethiopia where there agriculture serves as backbone of the economy and ensure well being of the people, the adverse effects of land use land cove change are diverse. Beside to 
this various water resource development sectors (hydropower, irrigation, urban and rural water supply etc.) have persistently been affected by both temporal and spatial changes of LULC [8].

The basic premise in using remotely sensed data for change detection is that changes in the objects of interest will result in changes in reflectance values or local textures that are distinguishable from changes which caused by atmospheric conditions, illumination and viewing angles. Because digital change detection is affected by spatial, spectral, thematic and temporal constraints, and since several change detection methods are possible to use, the choice of appropriate algorithm for a given research project is important Change detection process is to recognize LULC on digital images that change features of interest between two or more dates. Change detection encompasses the application of multi-date or multi-temporal data sets to differentiate areas of land cover change between dates of imaging [2].

Land use and land cover changes in response to urban growth also reported by some studies that, an expansion of urban areas annually from 1957 to 2009 has been identified by "Reference [2], shows that, in the urban fringe of Bahir Dara reaasa consequence of increasing population.. Expansion of the already existing urban fabrics through rapid construction sites of residential units, commercial and industrial units road and other impervious surfaces led to continuous expansion of built up surfaces in the different corners of the city". Another study of [8], on LULCC in Mekelle city, Ethiopia showed a positive change of $200 \%$ in urban area. The urban changes may be associated with population growth as well as industrial development during this period. Simultaneously, a close relationship of spatiall urban expansion was shown with the geometric center of a city and distance from major roads, indicating that most significant drive to urban expansion was road networks and pavements port and leisure facilities. Associated with the rapid expansion of urbanization, a lot of land has been converted from rural to urban [11]. From the land use and land cover change point of view, expansion of urban areas is of greater importance because of its strong effect on other land cover classes, such as agricultural lands, non-built areas, forests and others. Ethiopia, having the second largest population in Africa has a total of 105.6 million population in 2017 according to UN estimates [10]. It has a $2.49 \%$ of annual growth rate and having 5\% average annual urban growth rate. In spite of its low urbanization rate compared to other African countries, the impact of land use and land cover changes become a big challenge to the country. Satellite image pre-processing before change detection phenomenon is very important in order to establish a more direct affiliation between the acquired data and biophysical phenomena [1]. Due to acquisition system and platform movements, remotely sensed data from aircrafts or satellites are generally geometrically distorted. Satellite Remote Sensing and GIS are the most common methods for quantification, mapping and detection of patterns of LULCC because of their accurate geo-referencing procedures, digital format suitable for computer processing and repetitive data acquisition [7].

The Municipality of Nekemte town was established in 1934 and designated as a town in 1942. The first town plan was drawn in 1967. The total area of the town at the time of establishment was 197.6 ha, of which 27.17 ha was owned by few landlords. Eventually, due to population growth and governments center for administration, the town drew better attention for development, despite of the plan, experienced sprawled unguided over vast area. Nekemte Urban Local Government (NULG), administration of self-rule by the city was incorporated among the 20 selected cities in Oromia Regional State and reformed in 1997 E. C in accordance with the proclamation No. 65/2003. Nekemte town is one of a town in West Oromia, where urban expansion has been rapidly increasing during the last 25 years. The extent of such intensive urban land expansion at the expense of natural environment has not yet been studied in the area.

Therefore, it is required to determine the rate and trend of past land cover/use conversion for future urban development without affecting the natural environment. The study was carried out to analysis the effects of urban land use/ cover change dynamics on pre-urban environment in Nekemte town by using RS and GIS tools with more emphasis on forest, wetland, and surface water quality. The aim of the study was to evaluate the extent of urban land use transition and spatial trends of changes over the considered periods of time; and quantifying the effects of urban land use change on pre-urban natural environment (forest, wetland and surface water) and predicting the trends of urban land use/ cover changes.

\section{Methodology}

\subsection{Description of the Study Area}

Nekemte town is located $328 \mathrm{~km}$ West of Addis Ababa. It is the capital city of East Wollega Zone, Oromia Regional State, Ethiopia. The city has two layers of governmental structure: city government and sub-city administrations. The total demarcated area of the city is about 5380 hectares, but this research focused on the area currently under construction which is 1732.5 hectares of land. The study site lies at an altitude range of 2044 to 2168 meters above sea level (m.a.s.l).

\subsection{Population Dynamics}

According to national population and housing census conducted in 1996 the total population of Nekemte town was 50188. After 10 years in 2006, the total population was 65188 with an increment of about $23 \%$. In 2016, the total population has become 99334 which were projected from 2007 national census. The value increased by about $49 \%$ of the population of 1996 and $34 \%$ of the 2006 according to the Ethiopia Central Statistics Agency [4], (Figure 1). 


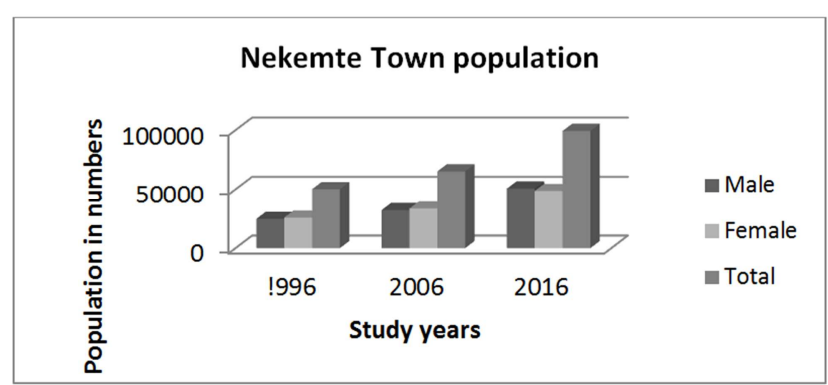

Figure 1. Population size of the study periods.

Rainfall data of the study period

Rain fall data of the study period (Figure 2) showed that rain fall distribution is almost similar but the total amount of annual rain fall has decreased from $2320 \mathrm{~mm}$ in 1996 to 2139.4 in 2006 and further reduced to $2044 \mathrm{~mm}$ in 2016.

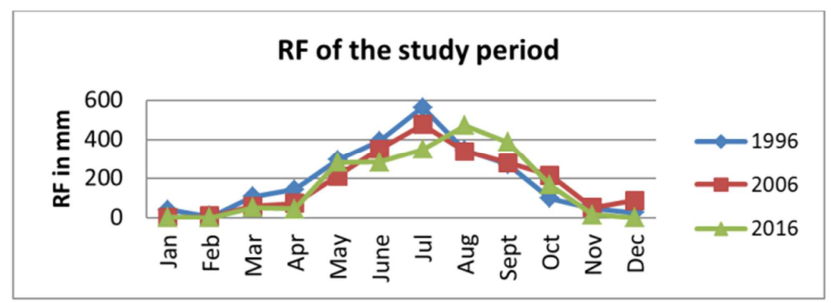

Figure 2. Rainfall distribution of the study period.

\section{Temperature}

As indicated in Figure 3 maximum temperature of each month was almost similar but the average temperature of the study years was increasing from 1996-2016. The average maximum temperature of 1996,2006 , and 2016 were $23.8^{\circ} \mathrm{C}$, $24.3^{\circ} \mathrm{C}$ and $25.5^{\circ} \mathrm{C}$ respectively. This trend showed that temperature has increased during the study period.

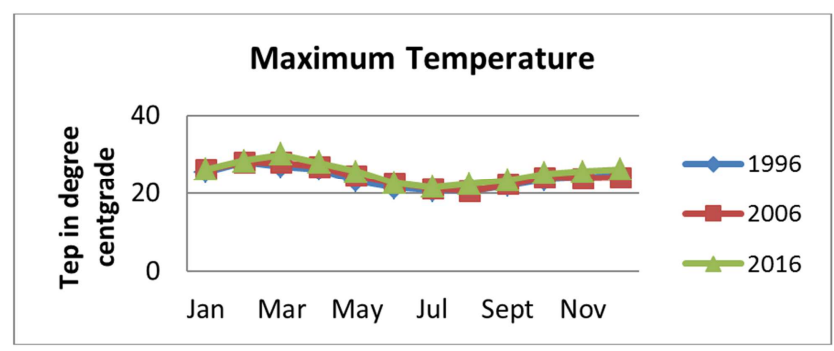

Figure 3. Maximum temperature of the study periods.

\subsection{Methods}

\subsubsection{Data Acquisition}

Land use land cover changes of the study were manually digitized from Google earth images; 1996, 2006 and 2016 at the months of September for each year. The digitized LULC of the study period was exported to Arc-GIS in KML format and convert feature classes into polygon. The ground truth data were collected in September 2016 by using Geographical Positioning System (GPS). Image preprocessing, area calculation and mapping were done by ArcGIS software.

All land use/ cover types of the study period were classified into six classes; namely, built-up area, cultivated land, forest, grazing land, riparian forest and wetland (Figure $4,6 \& 8)$. Each class was given unique identity and assigned a particular color to make them separate from each other. 10 training samples were collected for each classified and use/ cover type and a total of 60 were collected by using GPS, which used to test the accuracy level of classified LULC of the current study period (2016). In order to assess the effects of urban land use on water quality, water samples were taken twice in a month during peak rain seasons (July-September) and once for the rest of months from October, 2016 to June, 2017 and a total 42 samples from two sources, namely; Mino stream water located in forested area, with good vegetation cover and little disturbance from humans and assumed to be good water quality and Laga Merga stream water in urban built-up areas, with pavement and buildings, causing high runoff. The two study areas are found within the same agroclimate zone adjacent to each other. The stream water sample was taken to Laboratory of Ethiopian Environmental protection authority and analyzed for PH, Total Suspended Solid (TSS), Total Dissolved Solid (TDS), Total Nitrogen (TN), and Total Phosphorus (TP).

\subsubsection{Accuracy Assessment}

For the accuracy assessment of LULC extracted from Google earth images, stratification method was used to represent different land cover classes of the area. The accuracy was assessed by using ground truth data and aerial photograph. The comparison of classification results and reference data was carried out statistically using error matrices.

\subsection{Land Use/Cover Change Detection}

A two-way cross-matrix obtained by the application was used to describe the key change types in the study area. Cross tabulation analysis was conducted in order to determine the quantitative conversions from a particular category to another land cover category and their corresponding area was evaluated on pixel to pixel basis. Thus, a new thematic layer was also produced from the six class maps, containing different combinations of change classes.

Table 1. Description of LULC types.

\begin{tabular}{ll}
\hline Land classes & Description \\
\hline Built up area & $\begin{array}{l}\text { Urban fabric, industrial, commercial, road and non } \\
\text { vegetative land }\end{array}$ \\
Cultivated land & $\begin{array}{l}\text { Arable land, permanent crops, pastures and others } \\
\text { agricultural areas }\end{array}$ \\
Forest land & $\begin{array}{l}\text { Natural and manmade forest } \\
\text { Grazing land }\end{array}$ \\
Riparian forest & $\begin{array}{l}\text { forest cover along the river and stream bank } \\
\text { Water bodies or swampy area used as source of water } \\
\text { for Bone farm during dry season }\end{array}$ \\
\hline
\end{tabular}

\section{Results and Discussion}

\subsection{Land Use Transition and Spatial Trends of Change}

\subsubsection{Land Use / Cover Transitions (1996-2016)}

The study was intended to evaluate land use/ cover change 
of the three study periods, namely 1996, 2006 and 2016. Each of the land use/ cover map was compared with the reference data to assess the accuracy of the classification. The reference data were prepared by considering training sample points and field knowledge of the study site. Over all classification accuracy of Nekemte city during the year 2016 was $86.5 \%$. The major land use type shown by the three maps include built up, cultivated land, forest land, grazing land, riparian forest and wetland. Forest land includes both natural and plantation forest which was seen similar reflectance during classification. As indicated on map and percentage share of each class of 1996 "Figure 4 and 5", the greatest share of land use/ cover from all classes was builtup, which covers an area of 554.7 ha, contributing $32 \%$ of the total area. The forest land and grazing land cover areas were 298 ha $(17 \%)$ and 299 ha $(17 \%)$, respectively. The aerial coverage of cultivated land, wetland and riparian forest are 258 ha $(14.4 \%)$ and 244 ha $(14 \%)$ and 102 ha $(6 \%)$, respectively. In 1996 forest cover was $17 \%$ of the total land cover next to built-up and wetland cover was $14 \%$ of the total, which indicate that much of land were under forest and wetland cover during that period.

\section{Land cover Map 1996}

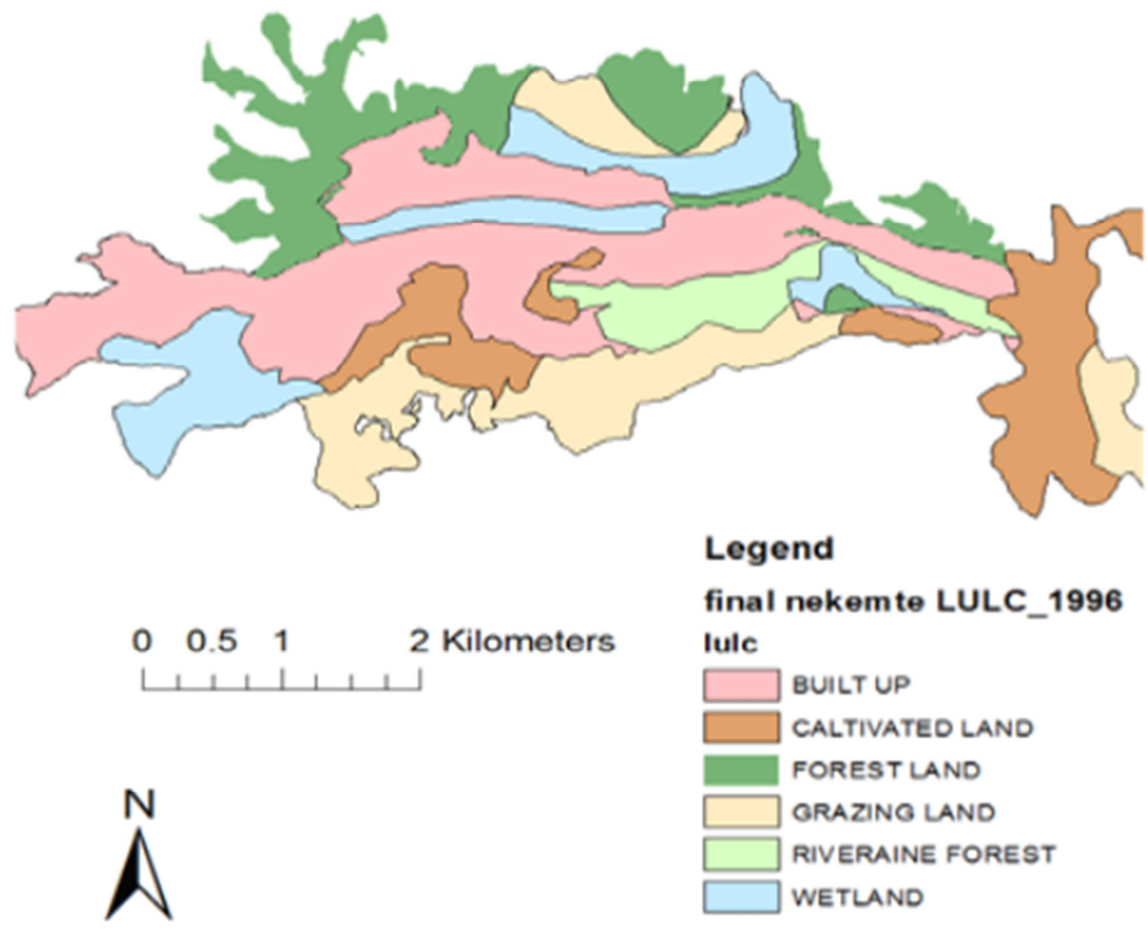

Figure 4. Nekemte Town land use/cover Map of 1996.

\section{Land cover in heactars}

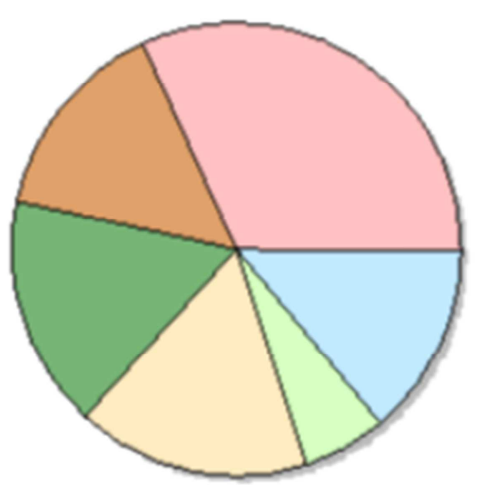

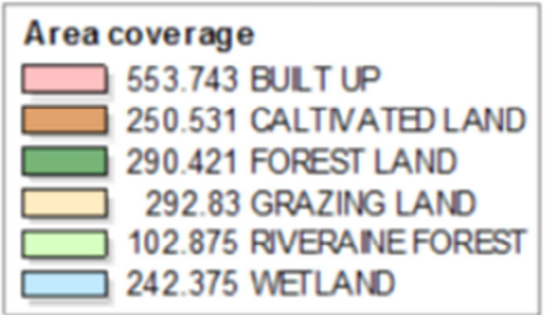

Figure 5. Area coverage in ha (1996).
As indicated on "Figure 6 and 7", area coverage of 2006, built-up area was increasing with the greatest share as compared to the rest of land use/ cover classes covering an area of 746 ha (43\%). Cultivated land covers an area of 464 ha $(27 \%)$ next to built up from the total areas. Grazing land, forest, riparian forest and wetland covers were reduced within ten years period and remain with an area of 189 ha $(11 \%), 168$ ha $(10 \%), 90$ ha $(5 \%)$ and 73 ha $(4 \%)$, 
respectively. Built-up area has been increased from $32 \%$ in 1996 to $43 \%$ in 2006 at the expense of forest, grazing, and riparian forest. This increment in build-up is due to population growth and rural to urban migration. Cultivated land cover was also increased to $27 \%$ in 2006 from $14 \%$ in 1996 , due to the conversion of more wetland to cultivated land during this period. Whereas, forest cover was reduced from $17 \%$ in 1996 to $10 \%$ in 2006 in which more of forest land was converted to built-up area. The wetland, which was $14 \%$ in 1996 , was reduced to $4 \%$ in 2006 as more wetland was converted to built-up and cultivated land.

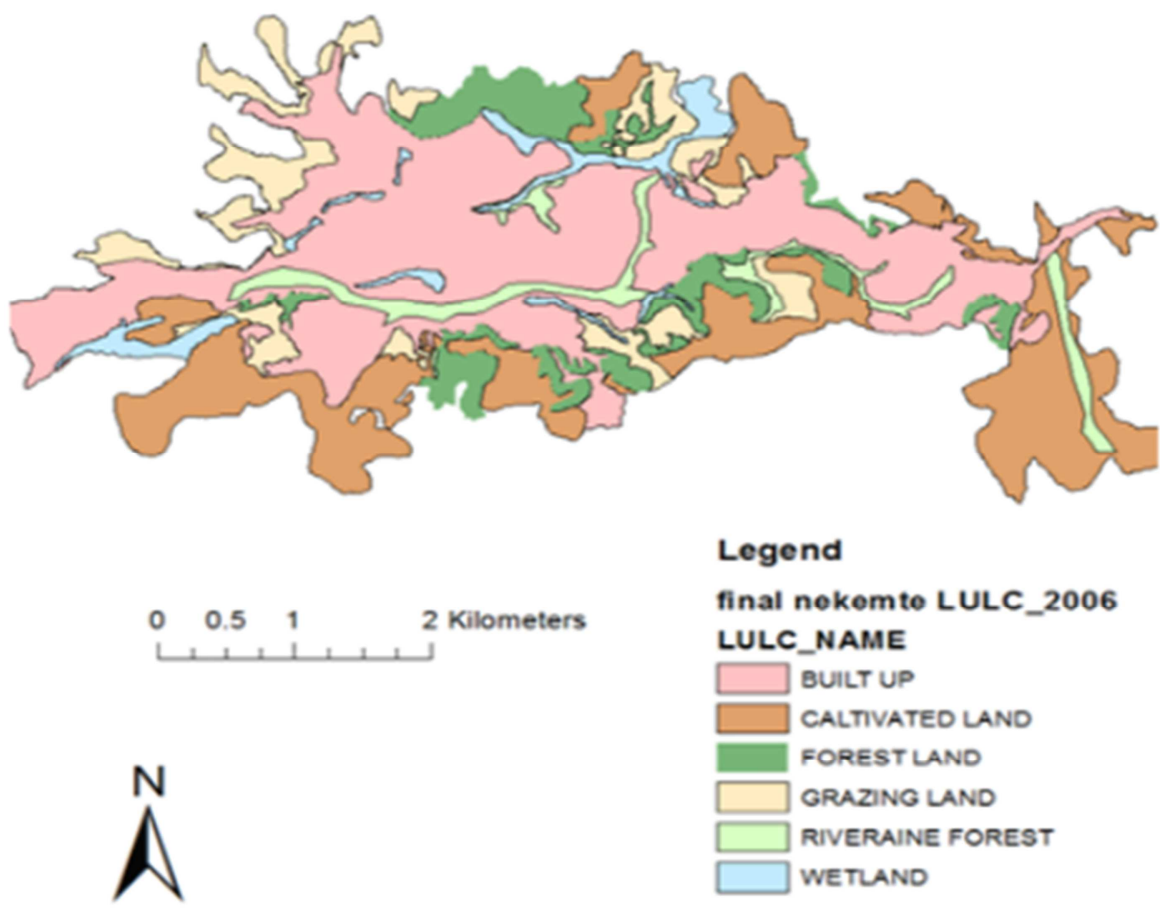

Figure 6. Nekemte Town land use Map of 2006.

\section{Land cover in heactars}

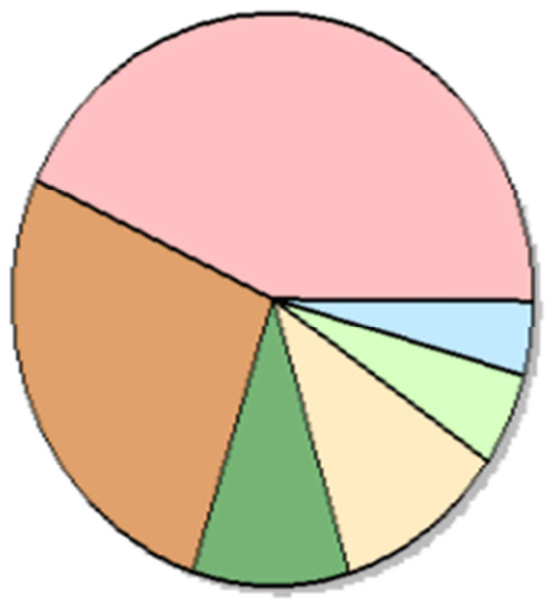

\section{A rea coverage}

746.115 BUILT UP

464.681 CALTNATED LAND

168.051 FOREST LAND

189.949 GRAZING LAND

90.897 RVERAINE FOREST

73.057 WETLAND

Figure 7. Area coverage in ha (2006).

As indicated on "Figure 8 and 9", land use land cover map and area coverage of built-up area in 2016 covers more areas than all other land classes, occupying 1321 ha $(76 \%)$ of the total land cover of the study area. Built-up areas have been increased during the study period. Forest and wetland coverage of 2016 was $5 \%$ and $3 \%$, respectively. Cultivated land, grazing land and riparian forest cover of the year was $10.4 \%, 3.1 \%$, and $3.6 \%$, respectively. 


\section{Nekemt Land cover Map 2006}

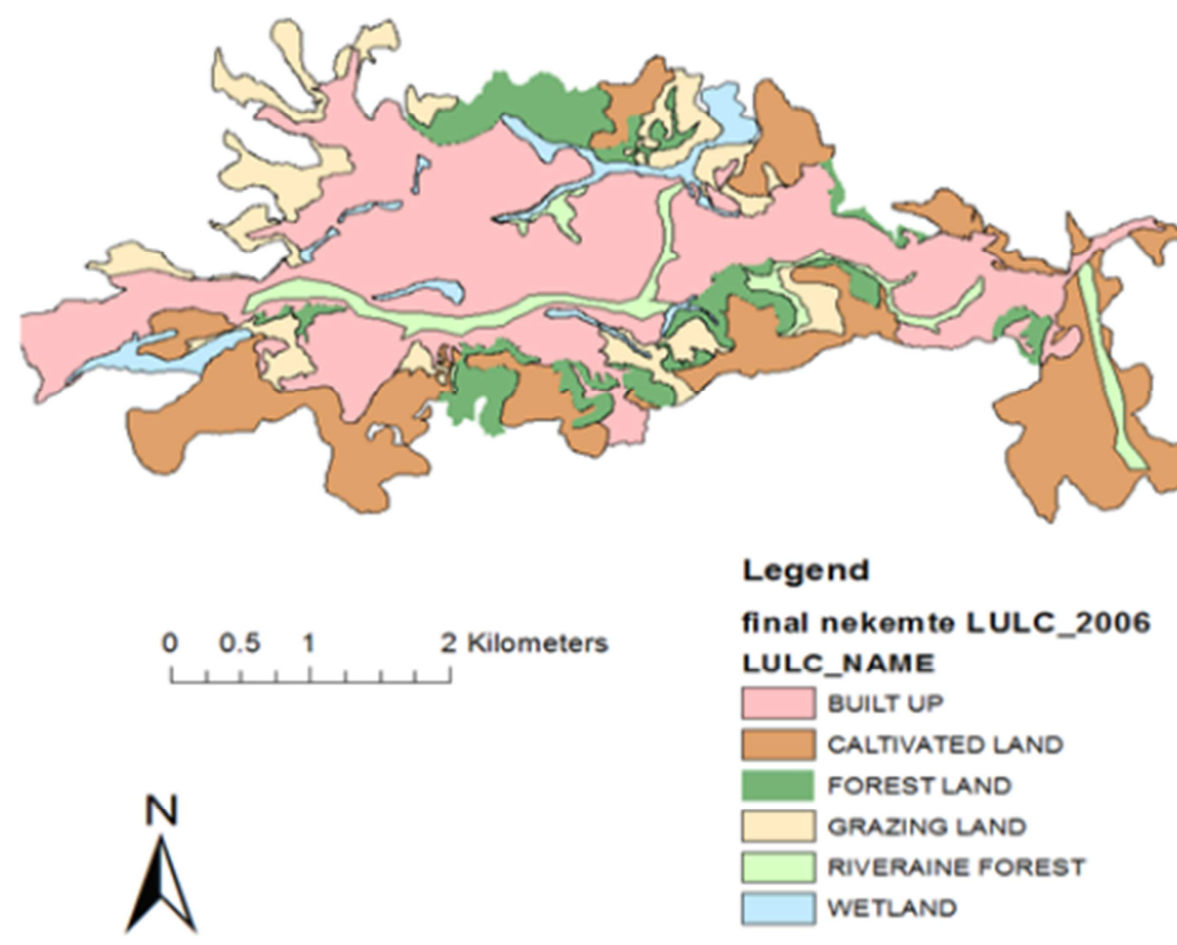

Figure 8. Nekemte Town land use Map of 2016.
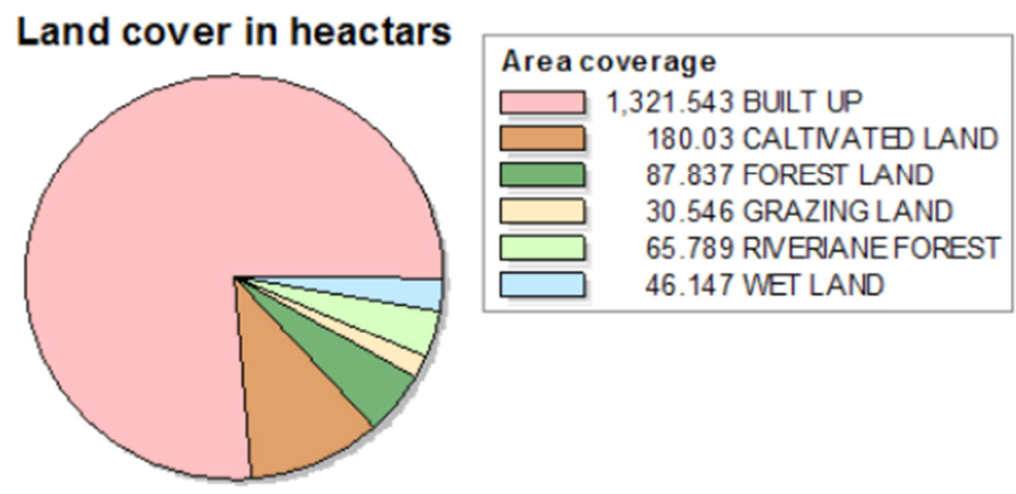

Figure 9. Area coverage in ha (2016).

"Table 2,"indicated that, area coverage of built up was increased with respective value of $35.5 \%$ in $1996,43 \%$ in 2006 and $70 \%$ in 2016; forest coverage of $17 \%$ in 1996 ,
$9.7 \%$ in 2006 and $5.1 \%$ in 2016 and wetlands coverage of $14 \%$ in $1996,4.2 \%$ in 2006 and $2.7 \%$ in 2016 , except built up area have showed decreasing trend.

Table 2. Nekemte Town LULC in Hectares; 1996, 2006 \&2016.

\begin{tabular}{|c|c|c|c|c|c|c|c|}
\hline Land Classes & 1996 & $\%$ & 2006 & $\%$ & 2016 & $\%$ & AARC (\%) \\
\hline Built up & 553.74 & 32.6 & 746 & 43.1 & 1321.5 & 76 & $3.65+$ \\
\hline Forest & 290.3 & 17 & 168.39 & 9.7 & 87.8 & 5.1 & $1.25-$ \\
\hline Cultivated & 250.5 & 15.6 & 464.7 & 26.8 & 180.7 & 10.4 & $2.3+\&-$ \\
\hline Wetland & 242.8 & 14 & 73.05 & 4.4 & 46.29 & 2.7 & $1.225-$ \\
\hline Grazing & 292.8 & 17 & 189.9 & 11 & 30.4 & 3.1 & $2.35-$ \\
\hline Riparian forest & 102.88 & 5.9 & 90.7 & 5.2 & 65.8 & 3.8 & $1.375-$ \\
\hline Total & 1732.74 & 100 & 1732.74 & 100 & 1732.74 & 100 & \\
\hline
\end{tabular}

a) Rate of change in percent is calculated as change in between the two study years per total change of those years divided by the time interval times 100 b) AARC $=$ Average Annual Rate of Change 


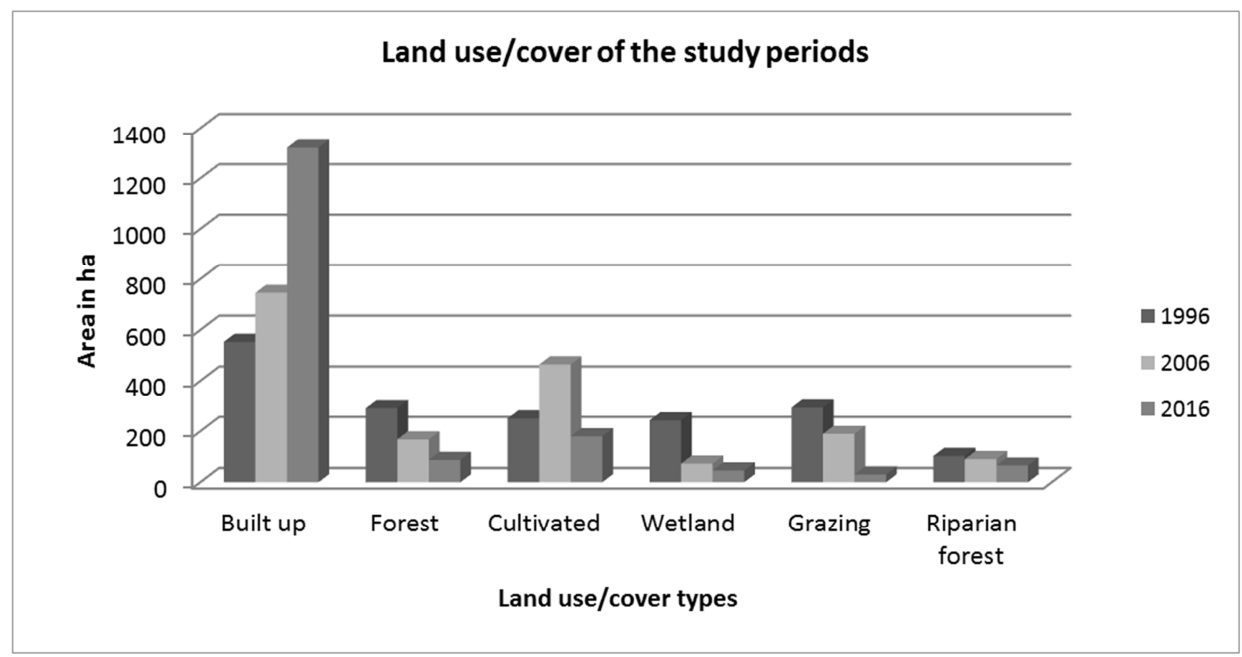

Figure 10. Land use \&cover status of the study period.

Built up area has increased between 1996 and 2006 by 181.16 ha within 10 years interval with a rate of 18.1 ha/year and further increased in 2016 with accelerated rate of change $47.01 \mathrm{ha} /$ year. The built up area was expanded at the expense of forest land, wetland, grass land and cultivated land. This shows that there was a dramatic expansion of built up area within the specified time period because of increased population pressure in the town. Forest land had decreased from 1996 to 2006 by 130 haat 13 ha/year rate of change and further decreased by 80.59 ha in 2006-2016 at rate of 8 ha/year. The rate of change was decreased in between 2006 to 2016 as compared to previous ten years because of some restriction and change of land distribution policy The change was induced by the conversion of shrub, forest and wetland to built-up due to increased population pressure in the city.

\subsubsection{Change Detection}

Change detection helps to determine the actual change of one land use class to the others land use classes. The method used in change detection was comparative analysis of LULC classifications for $\mathrm{t} 1$ and $\mathrm{t} 2$ produced independently. The total land area under the study was 1732 hectares. The land use land cover change matrix indicates the direction of change "Table $3 \& 4$ ". The values in each column indicate the unchanged value and change to others land cover classes and the value across each row indicates the unchanged value and change to other land cover class. As indicated in Table III, all figures in bold indicate unchanged areas of each land use/ cover type within ten years. More land use were converted to built up during the study periods. Built up area has been gained 299.8 ha of land from different land use type in 2006. This shows that built up area was increasing at the expense of other land uses, while the most affected were forest land and wetland in which102.5ha and 62.7 ha of land converted to built-up within 10 years intervals, respectively.

Table 3. Land use change matrix between 1996 and 2006.

\begin{tabular}{|c|c|c|c|c|c|c|c|}
\hline Land cover type & Built-up & Cultivated & Forest & Grazing & Riparian & Wetland & Total \\
\hline Built-up & 444 & 12.7 & 16.9 & 31.8 & 35.2 & 13.1 & 553.7 \\
\hline Cultivated & 74.7 & 128.8 & 20.6 & 3.2 & 17.9 & 5.3 & 250.5 \\
\hline Forest & 102.5 & 38.8 & 34.4 & 100 & 0.1 & 14.5 & 290.3 \\
\hline Riparian & 36.1 & 14.4 & 20.8 & 11.8 & 16.3 & 3.6 & 103 \\
\hline Wetland & 62.7 & 105.7 & 12.3 & 19 & 10.2 & 32.5 & 242.4 \\
\hline Total & 743.8 & 464.1 & 168.4 & 190.7 & 91.9 & 73.8 & 1732.7 \\
\hline
\end{tabular}

Table 4. Land Use Change Matrix between 2006 and 2016.

\begin{tabular}{|c|c|c|c|c|c|c|c|}
\hline Land cover type & Built-up & Cultivated & Forest & Grazing & Riparian & Wetland & Total \\
\hline Built-up & 686.9 & 9.9 & 13.2 & 10.4 & 14 & 9.4 & 743.8 \\
\hline Cultivated & 276.5 & 138.7 & 36 & 0.9 & 10.3 & 1.7 & 464.1 \\
\hline Forest & 109.7 & 25 & 6.5 & 1.5 & 24.5 & 1.2 & 168.4 \\
\hline Grazing & 159.8 & 6.5 & 14 & 0.1 & 9.7 & 0.6 & 190.7 \\
\hline Riparian & 70.3 & 0.5 & 0.9 & 12.5 & 6.9 & 0.8 & 91.9 \\
\hline Wetland & 16.7 & 0 & 18 & 5 & 0.9 & 33.2 & 73.8 \\
\hline Total & 1319.9 & 180.6 & 88.6 & 30.4 & 66.3 & 46.9 & 1732.7 \\
\hline
\end{tabular}

As indicated in "Table 4", from the total 743.8 ha of built up area in 2006 about686.9 ha of built up area was unchanged, which means more land areas remain as a built up area in 2016 as compared to other land use types. All figures in bold indicate those land uses, which were unchanged during the considered periods. Most of the land 
use types of the year 2006 were converted to built-up area in 2016. Built- up area had gained 633 ha of land from different land use type. This shows that built-up area was still increasing at the expense of other land use types and the most affected were forest lands and wetlands in which 161.9 ha and 40.6 ha of land were converted to other land use types within 10 years, respectively.

\subsubsection{Gain and Loss of Land Use and Cover Types}

The classified images "Figure 11" showed that, there were arapid land use/ cover changes from others land use types to built-up area. During the study periods, grazing land, forest and wetland areas were the most dynamic classes which contributed to the increases of built up areas. The built up areas has been continued to increase with again of 831.5 ha and only losses63.5 ha in the periods. Forest and wetland areas have been decreased during the three study periods in which both had lost 280.9 ha and 220 ha of land, respectively. The overall changes, which occurred over the last 20 years in forest areas, had indicated a decreases of 280.9 ha (representing a decrease of $16 \%$ of the total study area) and again of 79.5 ha $(4.5 \%$ of the study areas). Wetland areas has lost 228.8 ha (13.2\% of the study area) and gained $2 \%$ ha or $1.25 \%$ of the study area, but built up area has been gained $48 \%$ and lost only $3.6 \%$ land area of the total study area. The other land use and cover type (Cultivated land, grazing land and reverie forest) also lost their area coverage due to the expansion of urban built up area.

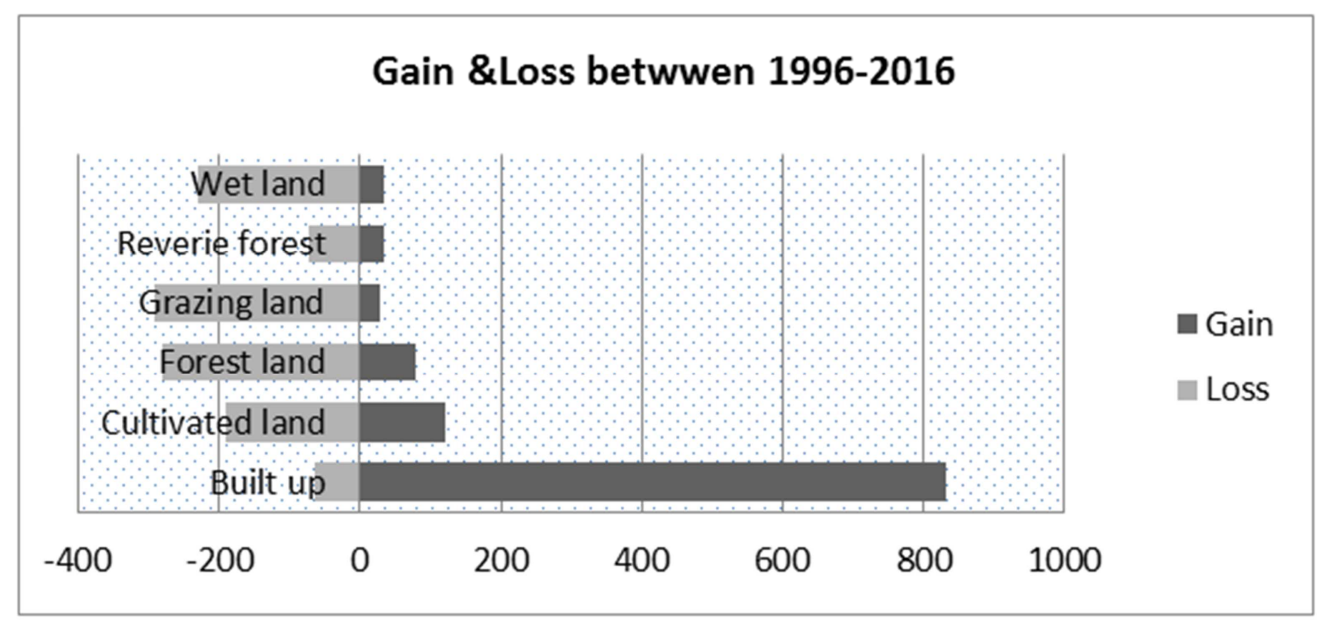

Figure 11. Gain and losses of land cover of each land uses (ha).

The reason for the change of large portion of other land uses to built-up area were due to rapid population increment during the considered period as indicated in population data of Figure 1. The rapid population growth in urban area was mainly resulted from high birth rate and migration of rural to urban areas. Such population increment had a plausible effect on the limited resources and had significantly contributed to the expansion of urban land by deforestation and infilling of wetland, cultivated, grazing and riparian forest areas.

\subsection{Effects of Urban Land Expansion on Natural Environment}

\subsubsection{Urban Land Use Change and Forest}

Forest cover of the study years (1996-2016) have been reduced by $121 \mathrm{ha}$ and remain with $168.3 \mathrm{~h}$ in year 2016 . Forest coverage was reduced by $70 \%$ and mean temperature of the same years was increased by $0.04^{\circ} \mathrm{c}$ within 20 years period. There were no overall trend for a reduction in rainfall over the study period (1996-2016), it would appear in a fluctuating trends. Forest cover predicts interannual variability in rainfall. So, the removal of forest cover due to urban land expansion has been contributed to mean annual local temperature increment and water quality reduction due to urban runoff in the study area

\subsubsection{Urban Land Use Change and Wetland}

Wetland, which is assumed to be the home for many plant and animals, source of water and areas for flood control was reduced from 242.8 ha (14\%) in 1996 to 46.29 ha $(2.7 \%)$ in 2016 196.51ha (13\%) within 20 years periods. Urban land expansion was the primary factor for the wetland area reduction and farming during dry period (Bone farm) and pollution of urban runoff are the other factors treating the normal function of the existing wetland in the study area. Wetland ecosystems are different from these other ecosystems, in which structural and functional overlap between terrestrial and aquatic systems. So, wetland area reduction and pollution resulted in the disappearance and disturbance of normal function of both ecosystems.

\subsubsection{Urban Land Use and Stream Water Quality}

As indicted in "Table 6", result of physco-chemical analysis showed that, urban land use had a negative impact on water quality. The mean effects of urban land use on $\mathrm{PH}$, Total suspended solid (TSS), Total dissolved solid (TDS), Total nitrogen (TN) and Total phosphorus (TP) of stream water were $5.4,26.11 \mathrm{mg} / 1,111.7 \mathrm{mg} / 1,4.41 \mathrm{mg} / \mathrm{l}$, and 0.74 $\mathrm{mg} / \mathrm{l}$, respectively, and the mean effects of non-urban land use on PH, TSS, TDS, TN, and TP of stream water were $5.08,2.13 \mathrm{mg} / \mathrm{l}, 55.6 \mathrm{mg} / \mathrm{l}, 1.35 \mathrm{mg} / \mathrm{l}$ and $0.0001 \mathrm{mg} / \mathrm{l}$, 
respectively. These higher in TSS, TDS and TN of urban land use as compared to non-urban land use were due to urban runoff, resulted from the removal of forest and wetlands. Land use changes have an effect on water quality, whether positive or negative. In forests and other areas with good vegetation cover and little disturbance from humans, most rainfall soaks into the soil rather than running off to the nearby stream, and water quality is relatively good as in the case of non-urban land use. In built-up areas with pavement and buildings, little rainfall soaks into the soil and causing high runoff to the surface water and poorer in water quality. The result of stream water quality indicators showed that, urban land use had a significant effect on water quality under all water quality parameters as compared to nonurban natural environment. Therefore, an increase in urban land use in the study area had a significant impact on value of TSS, TDS and TN of surface water.

After the analysis of all values, each variable was tested to find any statistical difference among the two land use/ cover types by using T-Tests. The result showed that, there were statistical difference in TSS, TDS and TN with p-value (0.02, 0.023 and 0.03 ), respectively, and no statistical difference in $\mathrm{PH}$, and $\mathrm{TP}$, at $95 \%$ confidence interval

Table 5. Mean Value of Physco-chemical parameters for the study areas.

\begin{tabular}{|c|c|c|c|c|c|c|}
\hline \multirow{2}{*}{ Water quality indictors } & \multicolumn{3}{|c|}{ Urban stream water } & \multicolumn{3}{|c|}{ Non-urban stream water } \\
\hline & $\operatorname{Max}$ & Min & Mean & $\operatorname{Max}$ & Min & Mean \\
\hline $\mathrm{PH}$ & 5.71 & 5.13 & 5.41 & 5.1 & 5.07 & 5.08 \\
\hline TSS mg/1 & 76 & 0.03 & 26.11 & 2.3 & 2 & 2.15 \\
\hline TDS mg/l & 179.3 & 51.5 & 111.7 & 56.4 & 54.8 & 55.6 \\
\hline $\mathrm{TN} \mathrm{mg} / \mathrm{l}$ & 10 & 0.0001 & 4.41 & 2.2 & 0.5 & 1.35 \\
\hline $\mathrm{TP} \mathrm{mg} / \mathrm{l}$ & 5.2 & 0.0001 & 0.74 & 0.0001 & 0.0001 & 0.0001 \\
\hline
\end{tabular}

\subsection{Predicted Land Use/Cover Change of the Study Area}

As indicated in "table 5", predicted future land cover change for the coming 10 years was estimated based on the annual rate of change calculated for 20 years. The predicted value indicated that, built up area will be continual increased at the expense of other land use area at decreasing rate as compared to the last 20 years, this is due to land policy of the region on land distribution. The policy gave a due attention on communal residential apartment called condominium, which tends to reduce the likely impacts of built up areas on other land use type by reducing its areal expansion.114.9 ha of others land use will be converted to built area within a given boundary and 38.08 ha of built area will be expanded outside of the previous year boundaries and the total land use of the study area will be 1770.58 ha within the coming 10 years.

Table 6. Predicted land cover change of the study area.

\begin{tabular}{lllll}
\hline \multirow{2}{*}{ Land classes } & $\mathbf{2 0 1 6}$ & \multicolumn{3}{l}{ Predicted (2026) } \\
\cline { 2 - 5 } & Area (Ha) & \% & Area (Ha) & \% \\
\hline Built up & 1321.5 & 76 & 1474.5 & 83.3 \\
Cultivated land & 180.7 & 10.4 & 114.8 & 6.5 \\
Forest land & 87.8 & 5.1 & 82.05 & 4.6 \\
Riparian forest & 65.8 & 3.8 & 24.05 & 1.6 \\
Grazing land & 30.4 & 1.8 & 30.18 & 1.7 \\
Wetland & 46.3 & 2.7 & 45 & 2.5 \\
Total & 1732.5 & 100 & 1770.58 & 100 \\
\hline
\end{tabular}

\section{Conclusion}

Urban land use/ cover dynamic analysis revealed that built-up areas has been increased during the study period and resulted in substantial reduction of forest area, cultivated land, grazing land, wetland and riparian forest. Forest and wetland which is the focuses of the research have been continuously decreased, due to fast growth of urban land. This land cover change on the category of built up surface exerting an incredible pressure on non-built up surfaces, in particular forest and wetland. Expansion of the urban land use was increasing through rapid construction sites of residential units, commercial and road networks and other impervious surfaces.

During the study periods forest cover has been reduced because of urban land expansion to a such land cover. These indicate that forest removal due to urban land expansion had been resulted in local climate change. Urban land expansion affect the wetland through area reduction and farming during dry period (bone farm) and pollution of urban runoff were treating the normal function of the existing wetland. Urban land expansion influences the normal function of water environment through pollution from urban runoff, due to the removal of wetland which used as pollution absorbents.

Therefore, urban land expansion due to population growth, migration and economic development at the expense of other land use has contributed for local climate change, surface water quality deterioration and reduction of the normal function of wetland ecosystem. Urban growth will continue to increase at the expense of other land use type, unless necessary corrective measures are taken.

\section{References}

[1] Abd El-Kawya OR, Rød JK, Ismail HA, Suliman, AS (2011). Land use and land cover change detection in the western Nile delta of Egypt using remote sensing data. Appl Geogr 31:483494

[2] Binyam B, Garedew E, Eshetu Z, Kassa H (2015) Land Use and Land Cover Changes and Associated Driving Forces in North Western Lowlands of Ethiopia. International Research Journal of Agricultural Science and Soil Science 5: 28-44 
[3] Haregeweyn, N., Fikadu, G., Tsunekawa, A., Tsubo, Mand Meshesha, D. T (2012). The dynamics of urban expansion and its impact son land use/land cover change and small scale farmers living near the urban fringe: A case study of Bahir Dar, Ethiopia. Landscape and Urban Planning, 106(2), 149157. doi:10.1016/j.landurbplan.2012.02.016.

[4] PCC (Population Census Commission) (2008). Summary and Statistical Report of the 2007 Population and Housing Census: Population Size by Age and Sex. PCC, FDRE Addis Abeba, Ethiopia.

[5] Rahman A, Kumar S, Fazal S, Siddiqui MA (2011). Assessment of land use/land cover change in the North-West District of Delhi using remotesensing and GIS techniques. J Indian Soc Remote Sens.

[6] Rawat, J. S., \& Manish, K. (2015). Monitoring land use/cover change using remote sensing and GIS techniques: A case study of Hawalbagh block, district Almora, Uttarakhand, India.

[7] Singh, A (1989). Digital change detection techniques using remotely sensed data. Int J Remote Sense 10(6):989-1003

[8] Tahir M, Imam E, Hussain, T (2013). Evaluation of land use/land cover changes in Mekelle City, Ethiopia using remote sensing and GIS. Computer Ecol Software 3(1):9-16.

[9] UN HABITAT (2007). State of the World Cities 2010/2011: Bridging the Urban Divide. United Nations Human Settlements Program, Nairobi, Kenya.

[10] UN Estimate (2017). World population Prospects, Revision.

[11] UNFPA (2013). http://www.unfpa.org/pds/urbanization.htm, accessed date December, 2013.

\section{Biography}

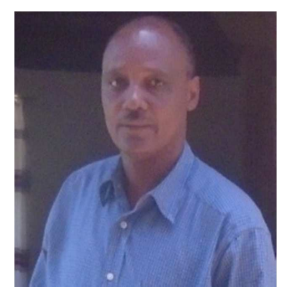

Tolera Megersa is a Ph.D. candidate in Environmental Science at Addis Ababa University and lecturer at department of Environmental Science at Wollega University. He has given integrated watershed management, land degradation and rehabilitation, Environmental disaster and risk management and Environmental impact assessment courses. 